\title{
TAXONOMIC AND BIOGEOGRAPHIC EVIDENCE ON THE RELATIONSHIPS OF AUSTRALIAN RAINFOREST PLANTS
}

\author{
Trevor Whiffin ${ }^{1} \&$ B. P. M. Hyland ${ }^{2}$ \\ (Accepted for publication 16.9.1983)
}

\begin{abstract}
Whiffin, Trevor' \& Hyland, B. P. M. ${ }^{2}\left({ }^{I}\right.$ Department of Botany, La Trobe University, Bundoora, Victoria, Australia 3083; ${ }^{2}$ CSIRO Division of Forest Research, Atherton, Queensland, Australia 4883) 1986. Taxonomic and biogeographic evidence on the relationships of Australian rainforest plants. Telopea 2(6): 591-610 - Further study of the biogeographic relationships of Australian rainforest plants must now proceed using specified groups that have been subjected to detailed taxonomic investigation. Two such groups are studied, the first comprising Syzygium and allied genera in the Myrtaceae (Syzygium, Acmena, Acmenosperma and Waterhousea) and the second Cryptocarya in the Lauraceae. The distributions of the Australian taxa in these groups are determined on the basis of the $1^{\circ} \times 1.5^{\circ}$ grid system; these distributions are then reduced to a number of geographic units, 11 within Australia and three outside. These data are then used to determine alternately floristic regions and floristic elements for: each taxonomic group in turn. The relationships between the floristic regions and the floristic elements for the two groups are discussed. Centres of diversity and centres of endemism within Australia are determined, and the possible relationships between these and the evolutionary history of the two taxonomic groups are briefly discussed. For the two groups considered, there are two major centres of diversity and endemism (north-eastern Queensland and south-eastern Queensland-northern New South Wales) and two minor centres (Cape York and Northern Territory), which probably represent centres of isolation and long-term refuges for rainforest flora. Other areas appear to be immigrant areas, receiving their flora from one or more of the centres of isolation.
\end{abstract}

\section{INTRODUCTION}

The major biogeographic and floristic relationships of Australian rainforests have been established by Webb \& Tracey (1981a, b). These studies determined the major floristic regions within Australia, and documented their generic and specific compositions. Such studies provide a sound basis for further study; however, they are essentially broad-scale comparisons, and further insights into the relationships of Australian rainforest plants must come from studies based on specified rainforest genera.

Many rainforest genera are poorly known, and hence detailed studies on their biogeography and evolution would not be warranted; the results obtained might well be misleading, and would in any case be subject to revision as taxonomic study progressed. The two groups selected for detailed investigation here are currently in an advanced stage of taxonomic study, and it is believed that the vast majority of their taxa have been collected and recognized. Hence it is felt that a more detailed study of these groups is justified, and that it will provide the first of additional insights into the relationships and lines of evolution in Australian rainforest plants. Certain aspects of the biogeographic relationships of these groups are presented here. Further studies are underway in an attempt to obtain detailed quantitative data on the relationships of the various taxa within these groups; this will lead to a study of the possible lines of evolution within the groups. Such information, when obtained, can then be 
integrated with the biogeographic data presented here in order to obtain a more detailed picture of the relationships of the Australian rainforest flora.

\section{Syzygium and allied genera (Myrtaceae)}

Recent work on the Australian representatives indicates that the division between Syzygium and Eugenia (Schmid 1972, Briggs \& Johnson 1979) should be recognized here, and that some, but by no means all, of the segregate genera should be recognized (Hyland 1983). Eugenia s. str. is a large genus, with over 1000 species. It is basically American, but extends to southern Africa and the Pacific area. There is only one species of Eugenia in Australia (Hyland 1983), and this is widely distributed outside of Australia. As it is part of a different evolutionary line to Syzygium and allied genera, it is not considered here.

Within the Acmena alliance of Briggs \& Johnson (1979) there are four genera recognized within Australia (Hyland 1983). They are believed to represent the same evolutionary line, and thus are considered together; throughout this paper they will be referred to as Syzygium and allied genera.

The genus Syzygium is distributed from Africa through Asia and Malesia to the Pacific, with about 500 species; its centres of concentration include South-East Asia, Indonesia and New Guinea. Within Australia there are 52 species, with 41 of these being endemic, but Hyland (1983) has indicated that there appears to be greater morphological diversity within Australia than there is in Malaysia, which has over 200 species. The genus Acmena is found from Asia through Malesia to Australia, with about 15 species. Within Australia there are seven species, of which six are endemic. The genus Waterhousea has four species, and is confined to Australia. The genus Acmenosperma has two species, one widespread and very polymorphic, extending from India and China to Australia, and the other an Australian endemic.

\section{Cryptocarya}

The Lauraceae appear to be a natural family, consisting of a group of closely related genera. As with other natural families, generic delimitation proves difficult, and genera are often separated on seemingly trivial morphological characters (Hutchinson 1964). Leaving aside the leafless parasitic climber Cassytha, there are six genera in Australia and, reflecting the situation in the family as a whole, they are not easily nor naturally recognized, and many species may be incorrectly placed as to genus. Cryptocarya is, however, basically distinct from the other five genera, in Australia at least.

There are approximately 250 species in Cryptocarya, and it is one of the few genera of Lauraceae to be common in both tropical Asia and tropical America. Within Australia there are 41 species, and all but three of these are endemic (Hyland in prep.).

\section{MATERIALS AND METHODS}

For the purposes of this study, the various subspecies were treated as separate units, as they generally had distinct geographic distributions. Thus within Syzygium and allied genera there were 69 taxa (in 65 species), and within Cryptocarya there were 42 taxa (in 41 species). The distributions of the taxa within Australia were mapped on the basis of the $1^{\circ} \times 1.5^{\circ}$ grid that is becoming standard in Australian biogeographic studies (cf. Hopper \& Maslin 1978). 
From these data it is possible to proceed in two directions (Jardine 1972, Birks 1976). Firstly, the various taxa may be used to determine the relationships of the geographic areas, hence to delimit floristic regions. Secondly, the taxa may be grouped according to their geographic distributions, to determine floristic elements. Both procedures are undertaken here.

It would have been possible to use the data as produced above, in terms of the distribution of each taxon in the grid squares. However, a rather large number of grid squares have only one or two taxa, and so it is preferable to group neighbouring grid squares together, to produce geographic units. These units are based on the centres of density of the taxa (Figs 1 and 2), and on a general knowledge of the distribution of rainforest within Australia. Thus 11 geographic units were distinguished within Australia (Fig. 3), and three outside of Australia. The extra-Australian units relate only to the distribution of Australian taxa to these regions, and are designated as New Guinea, Malesia, and 'widespread', the latter referring to distribution beyond New Guinea and Malesia.

The distribution of the 69 taxa of Syzygium and allied genera and of the 42 taxa of Cryptocarya in terms of these 14 geographic units was determined, and the data used alternately to delimit floristic regions and floristic elements. It should be emphasized that the data relate to Australian taxa only. Thus the data on extra-Australian regions become important only when considering floristic elements; nothing can be said concerning the floristic relationships of these non-Australian areas on the basis of the present data.

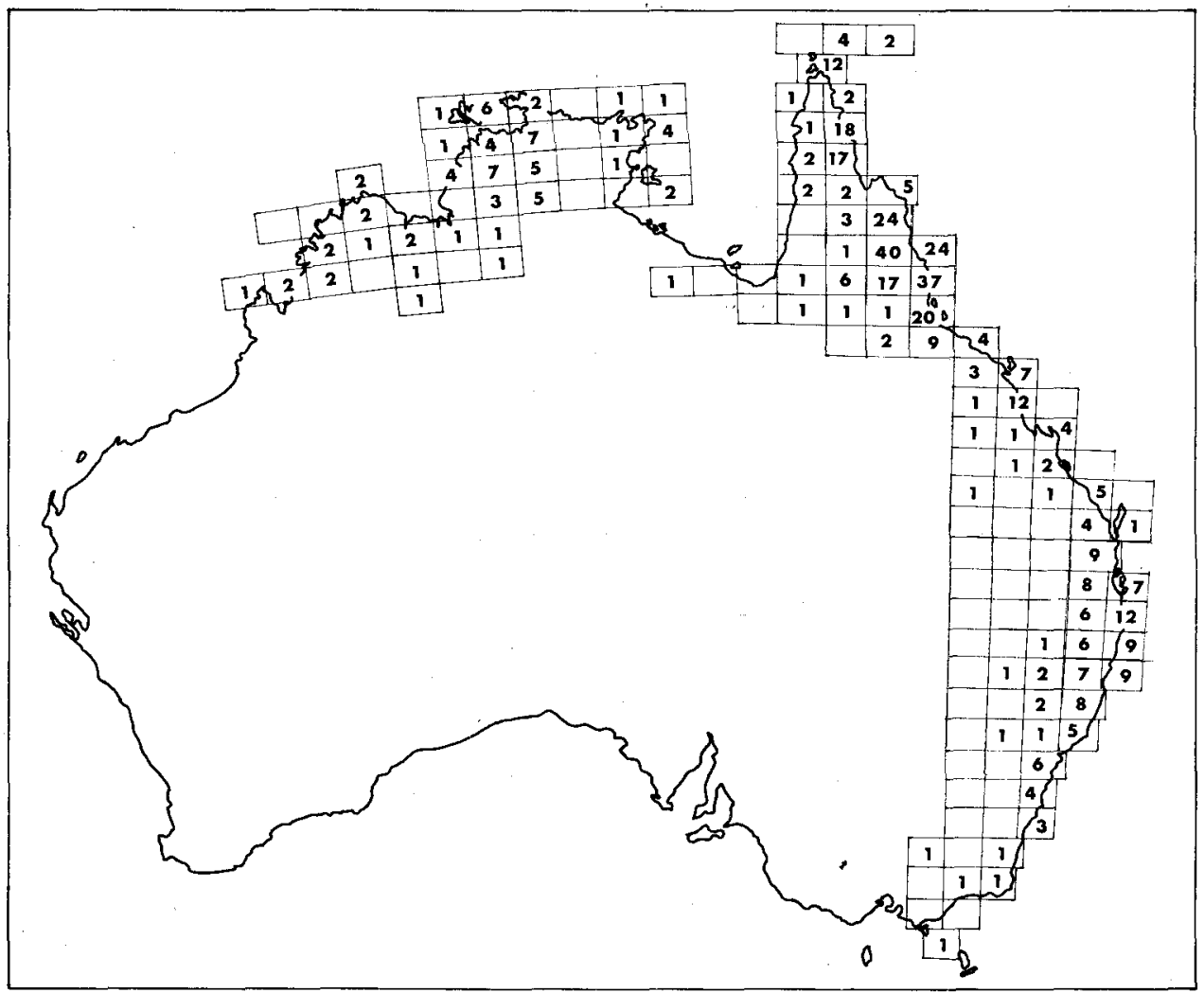

Figure 1. Number of taxa of Syzygium and allied genera in the $1^{\circ} \times 1.5^{\circ}$ grids corresponding to the Division of National Mapping 1:250000 topographical survey maps. 


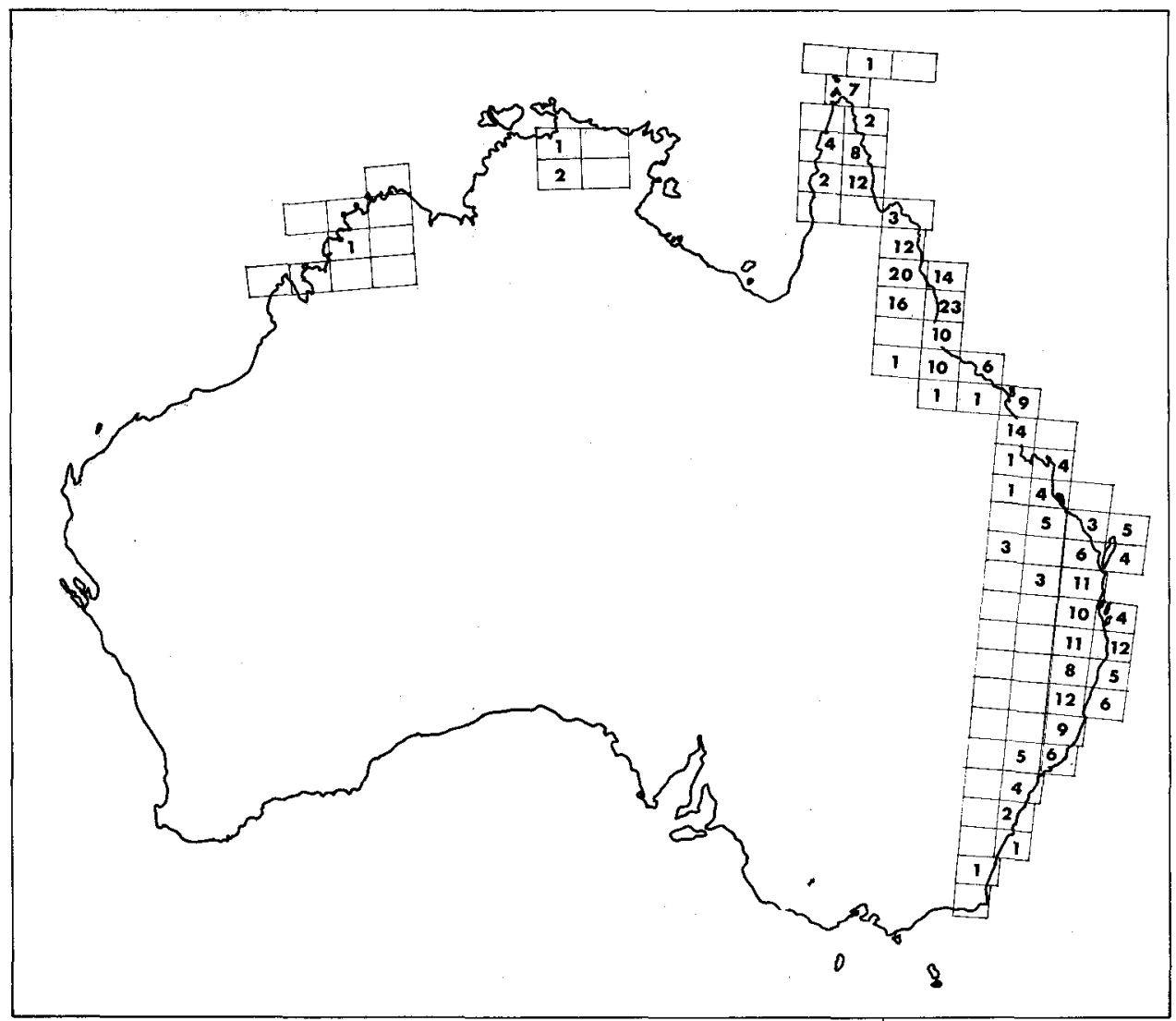

Figure 2. Number of taxa of Cryptocarya in the $1^{\circ} \times 1.5^{\circ}$ grids corresponding to the Division of National Mapping 1:250000 topographical survey maps.

The determination of floristic regions was based on the data sets involving the 69 or 42 taxa in each case. However, for the floristic elements it was noted that in each case a number of taxa had identical distribution patterns in terms of the 14 geographic units. In order to reduce the possible effects of group size in the numerical analyses (Clifford \& Williams 1973), the data sets for floristic element determination were reduced to the number of discrete distribution patterns. In Syzygium and allied genera, the 69 taxa showed 29 distribution patterns; the forms of these patterns are indicated in Table 1, and the compositions in Appendix 1. In Cryptocarya, the 42 taxa showed 18 distribution patterns; the equivalent information is provided in Table 3 and Appendix 2.

The similarity measure used in each analysis was the Jaccard co-efficient. This ignores negative matches, so that it does not count mutual absences as a similarity. Hence it is commonly used in biogeographic studies (Jardine 1972, Birks 1976, Webb \& Tracey 1981a).

For the four sets of data (floristic regions and elements for the two taxonomic groups), three analyses were undertaken. The similarity matrix was input in turn to a cluster analysis using the weighted pair group method (WPGMA), to an ordination using principal co-ordinates analysis, and to computation of a minimum spanning tree; further details are provided by Whiffin (1982). 


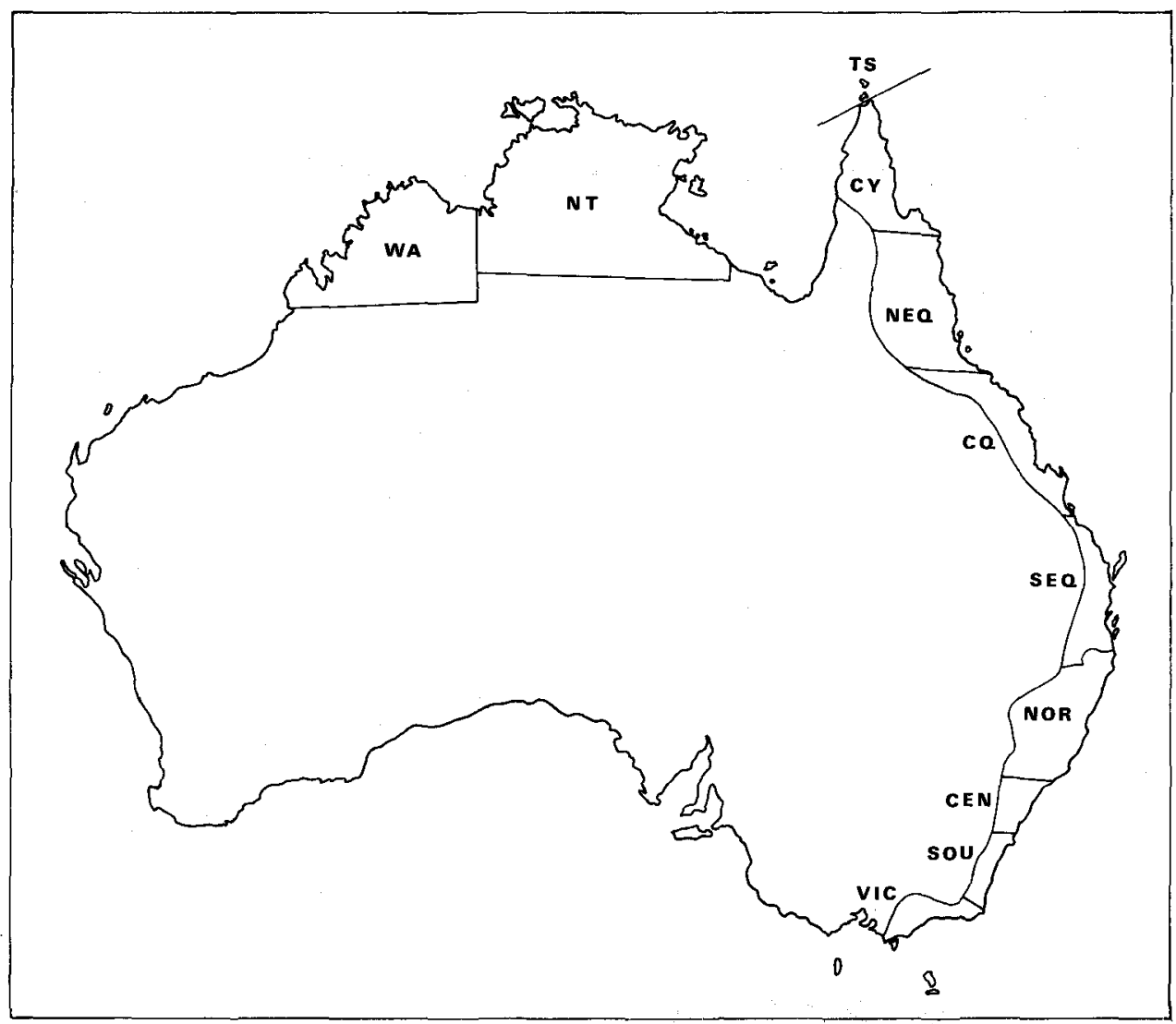

Figure 3. The 11 geographic units within Australia used for the determination of floristic regions and floristic elements.

\section{RESULTS AND DISCUSSION}

\section{Floristic regions from Syzygium and allied genera}

In the cluster analysis of the 11 geographic units (Fig. 4) it can be seen that the major division is between the basically southern areas, from central Queensland southwards, and the basically northern and western areas. The five-group level provides a convenient classification, and these five groupings are here termed floristic regions. These five floristic regions are designated:

(i) northern floristic region, comprising Torres Strait

(ii) north-western floristic region, comprising Western Australia and Northern Territory

(iii) north-eastern floristic region, comprising Cape York and north-eastern Queensland

(iv) south-eastern floristic region, comprising central Queensland, southeastern Queensland, and northern New South Wales

(v) southern floristic region, comprising central and southern New South Wales and Victoria.

The analysis of these geographic units by ordination shows a similar pattern of relationships (Fig. 5), and is more informative on the interrelationships of the floristic regions. The primary division in the ordination is between the three 


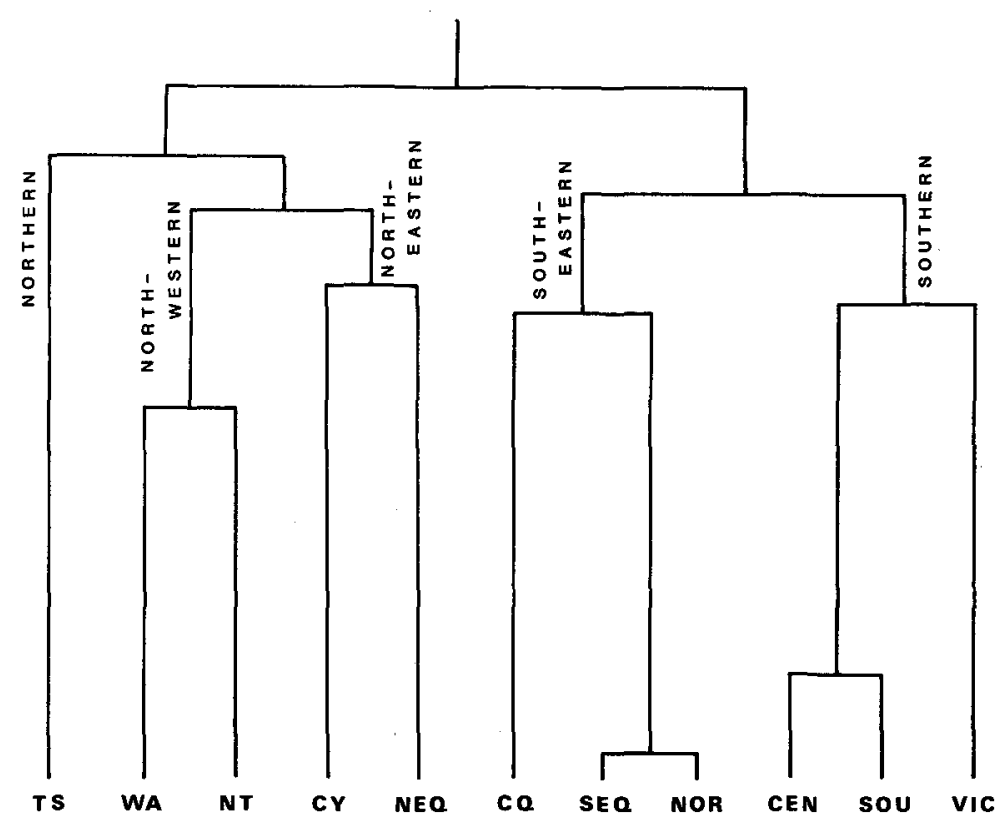

Figure 4. Cluster analysis of the 11 Australian geographic units in Syzygium and allied genera showing the five floristic regions recognized.

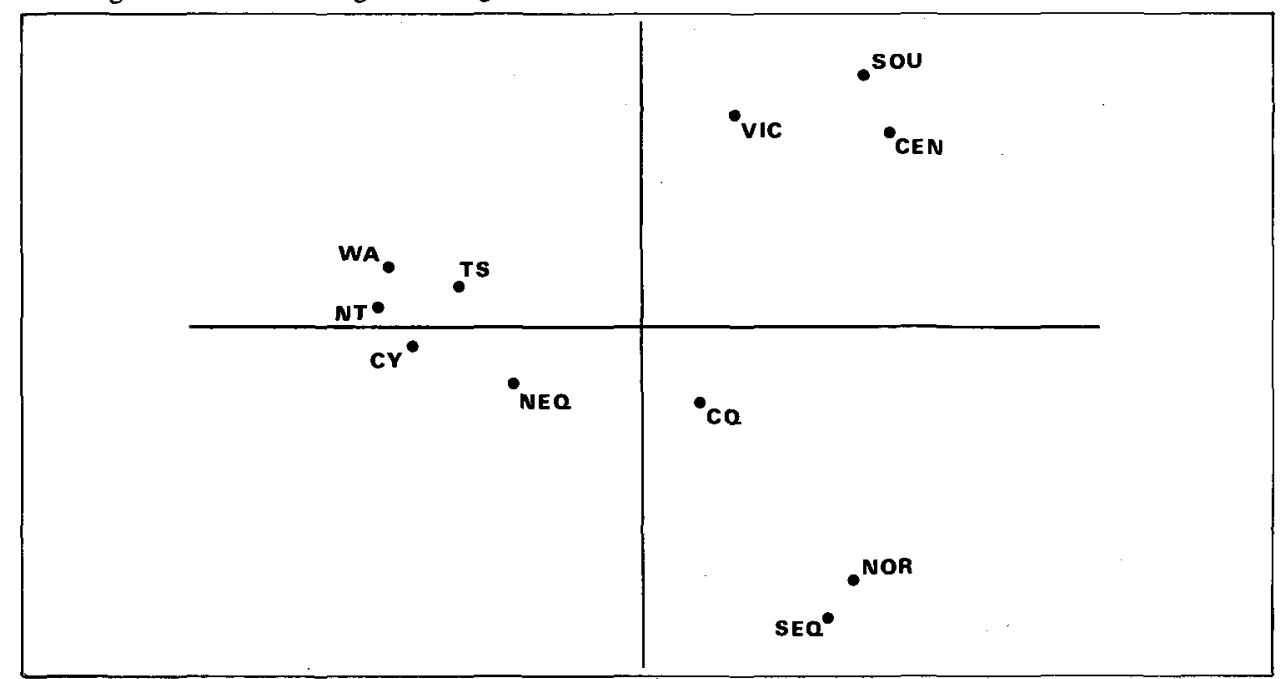

Figure 5. Principal co-ordinates analysis ordination of the 11 Australian geographic units in Syzygium and allied genera (axis 1 accounts for $25 \%$ of the variation, and axis 2 for $18 \%$ ).

$$
\text { WA }-N T-C Y-N E Q-C Q-S E Q-N O R-C E N-S O U-V I C
$$

Figure 6. Minimum spanning tree of the 11 Australian geographic units in Syzygium and allied genera. 


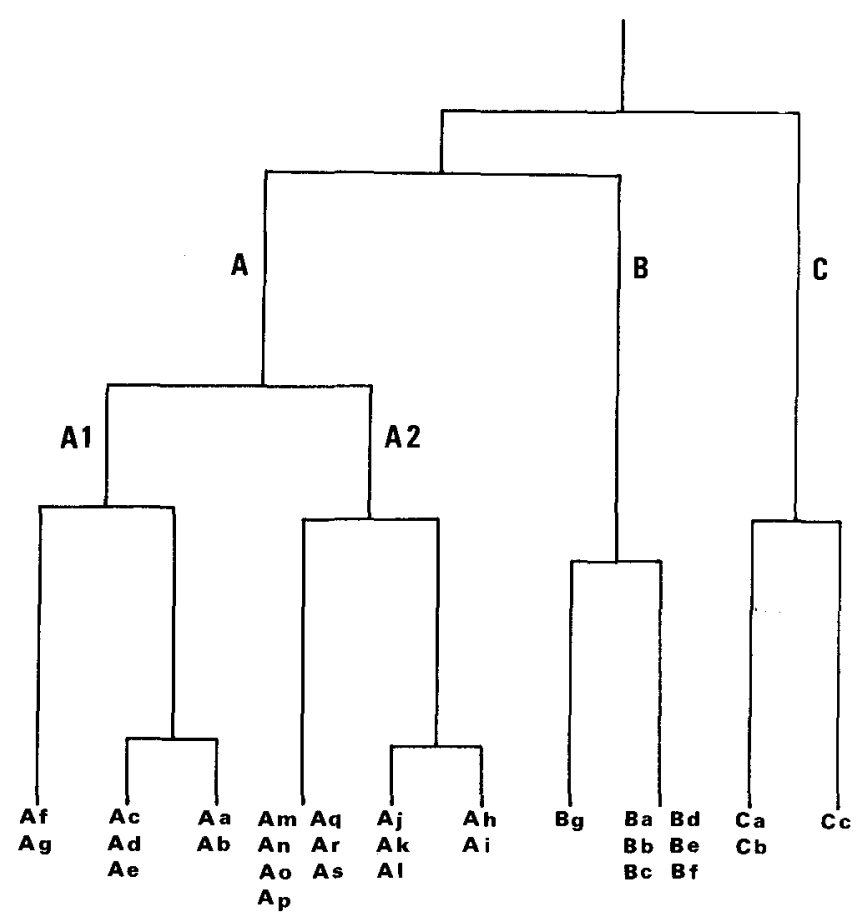

Figure 7. Cluster analysis of the 69 taxa (29 distribution patterns) of Syzygium and allied genera showing the four floristic elements recognized.

northern regions on the one hand and the two southern regions on the other. The southern and the south-eastern regions are shown to be quite distinct, whereas the three northern regions are more generally similar, although there are differences on later axes. Central Queensland appears in the ordination plot more or less midway between south-eastern Queensland and north-eastern Queensland; it thus appears to be equally related to both areas, and its position in the hierarchical cluster analysis could be misleading. In a similar way the position of Cape York in the cluster analysis might obscure its general similarity to a number of other areas, including Torres Strait and Northern Territory. The position of the geographic units in the minimum spanning tree (Fig. 6) is also generally supportive of the recognition of these floristic regions.

\section{Floristic elements in Syzygium and allied genera}

The cluster analysis of the 69 taxa (29 distribution patterns) on the basis of their distribution indicates that there are three major groupings, one of which is further divided into two (Fig. 7, Table 1). These four groupings are here termed floristic elements.

Floristic element $\mathrm{A} 1$ is basically a northern element, and contains 12 taxa that are generally centred on Cape York or Torres Strait. Five of these taxa are endemic to Cape York, while the others extend into New Guinea and Malesia.

Floristic element A2 is the largest element, with 41 taxa, all of which are to be found in north-eastern Queensland. Twenty-three of these taxa are endemic to north-eastern Queensland; of the other 18, a few extend southwards, while more extend northwards into Cape York and beyond, or westwards into Northern Territory and Western Australia. 
TABLE 1. DISTRIBUTION PATTERNS IN SYZYGIUM AND ALLIED GENERA, INDICATING THE FOUR FLORISTIC ELEMENTS RECOGNIZED

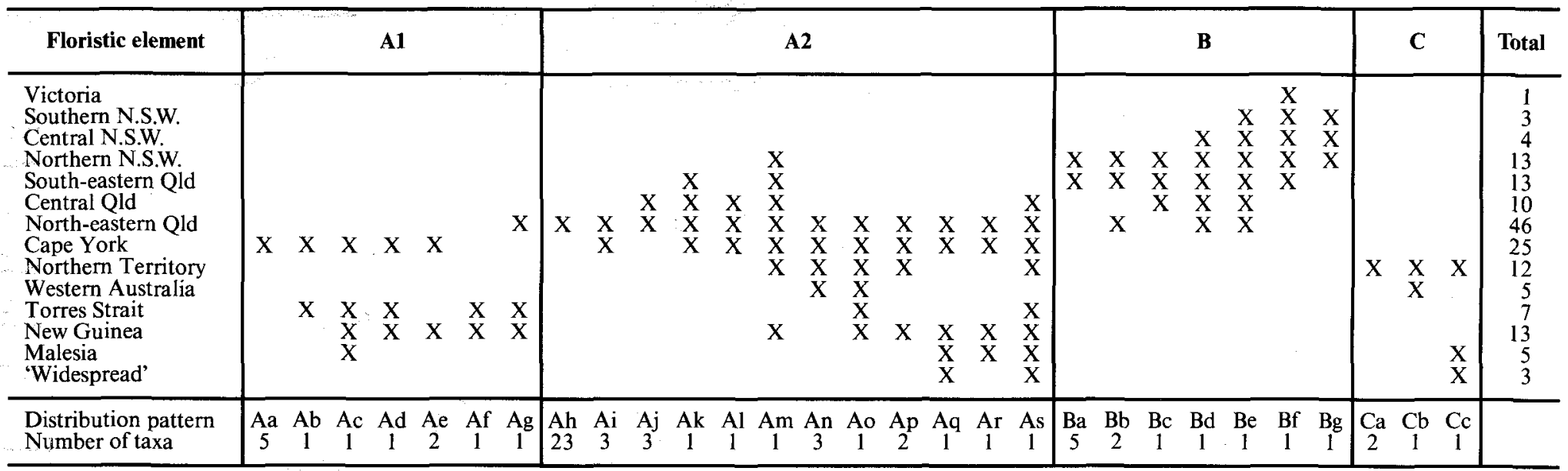




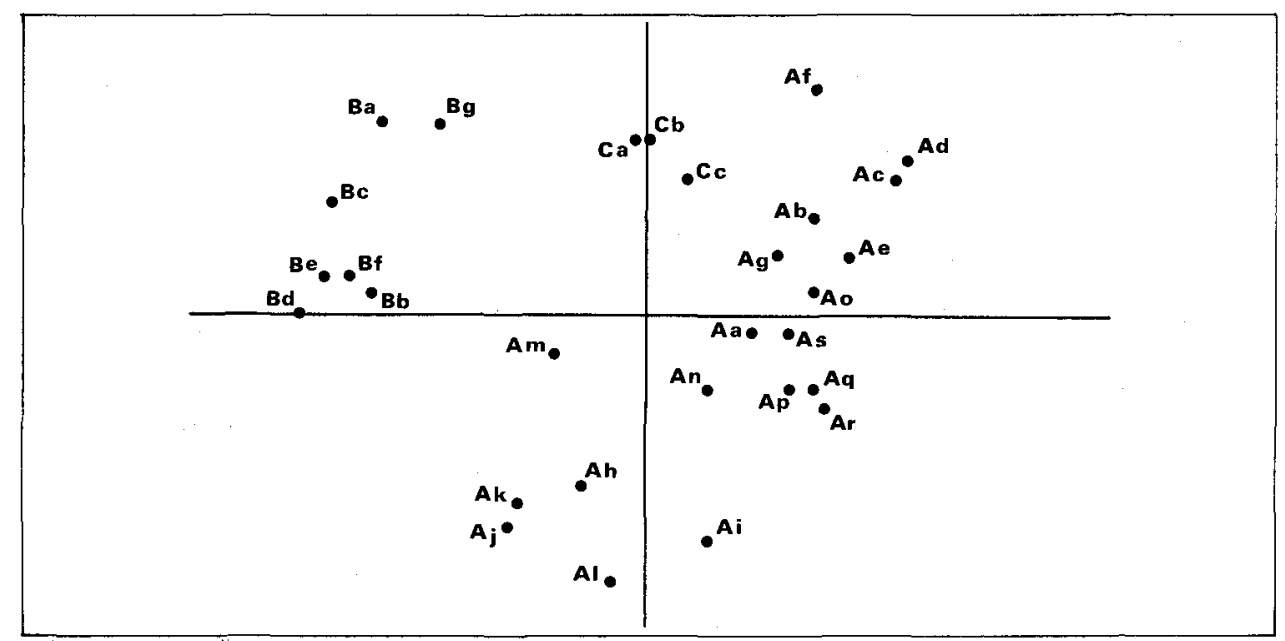

Figure 8. Principal co-ordinates analysis ordination of the 69 taxa (29 distribution patterns) of Syzygium and allied genera (axis 1 accounts for $21 \%$ of the variation, and axis 2 for $12 \%$ ).

Floristic element B is basically a southern element, and all 12 taxa in this group are to be found in northern New South Wales. Five taxa are endemic to south-eastern Queensland-northern New South Wales, while four taxa extend to north-eastern Queensland and four to central New South Wales; this number gradually decreases southwards, and one taxon reaches Victoria.

Floristic element $\mathrm{C}$ contains only four taxa, and is basically a north-western element. These taxa are found in Northern Territory, where two are endemic, while one extends to Western Australia and one northwards to Malesia and beyond.

The analysis of these taxa by ordination (Fig. 8) also indicates a similar distinction of four floristic elements, and provides additional information on the interrelationships of the elements. This analysis shows that the major division is between the southern element (B) on the one hand, and the northern (A) and north-western (C) elements on the other; floristic element $\mathrm{C}$ is reasonably distinct on the first two axes (Fig. 8), and clearly distinct on the third axis. Floristic elements $\mathrm{B}$ and $\mathrm{C}$ are generally distinct from one another, and from element A. Floristic elements $\mathrm{A} 1$ and $\mathrm{A} 2$ approach one another quite closely but, taking all analyses into account, can be distinguished.

The minimum spanning tree (Fig. 9) generally supports the recognition of these four floristic elements, except that it indicates that element $C$ is not a single distinct element, but rather has two lines of relationship with element A2. This is at variance with the results from the cluster analysis and ordination discussed above.

\section{Comparison of floristic regions and floristic elements in Syzygium and allied genera}

The relationships between the floristic regions and the floristic elements in Syzygium and allied genera may be seen in Table 2. Together with the distribution data in Table 1, this tends to indicate that while there is a relationship between the floristic regions and the floristic elements, it is not an absolute one. The north-eastern floristic region contains two distinct floristic elements, A1 centred on Cape York and A2 centred on north-eastern Queensland. The south-eastern floristic region is clear, basically containing 


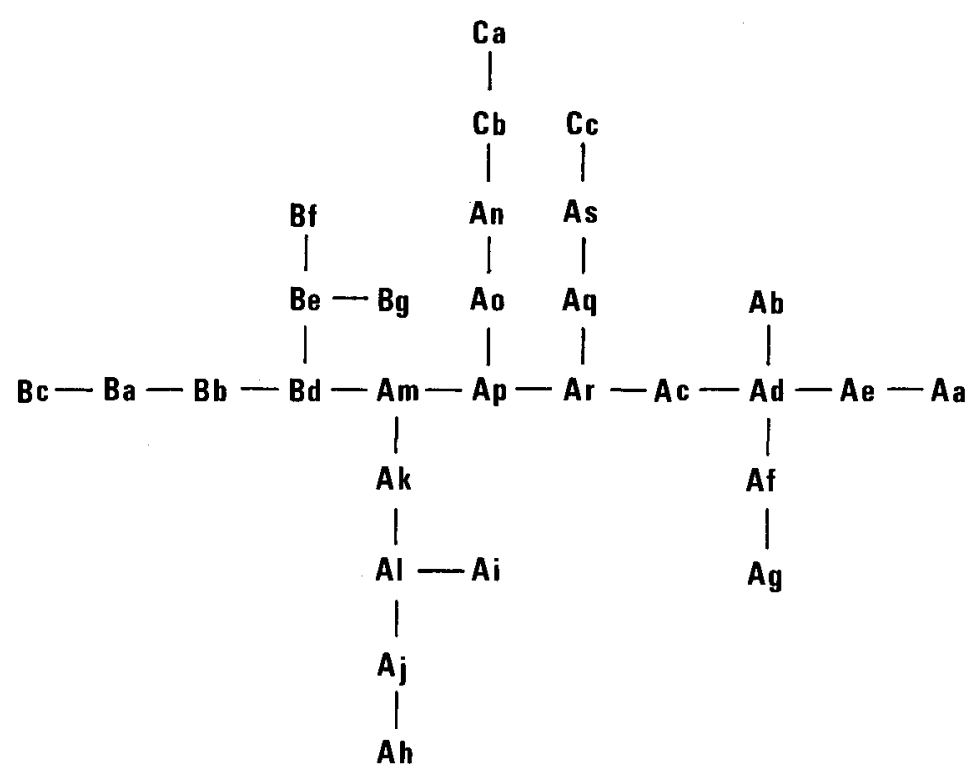

Figure 9. Minimum spanning tree of the 69 taxa (29 distribution patterns) of Syzygium and allied genera.

TABLE 2. SPECIES IN COMMON BETWEEN FLORISTIC ELEMENTS AND FLORISTIC REGIONS IN SYZYGIUM AND ALLIED GENERA

\begin{tabular}{ccccccc}
\hline \multirow{2}{*}{$\begin{array}{c}\text { Floristic } \\
\text { element }\end{array}$} & \multicolumn{3}{c}{ Floristic region } & Number \\
\cline { 2 - 6 } & north-western & northern & north-eastern south-eastern & southern & of taxa \\
\hline A1 & 0 & 5 & 11 & 0 & 0 & 12 \\
A2 & 8 & 2 & 41 & 7 & 0 & 41 \\
B & 0 & 0 & 4 & 12 & 4 & 12 \\
C & 4 & 0 & 0 & 0 & 0 & 4 \\
Total & 12 & 7 & 56 & 19 & 4 & \\
\hline
\end{tabular}

floristic element B, which is centred on south-eastern Queensland and northern New South Wales. The north-western floristic region likewise is reasonably clear, containing floristic element $\mathrm{C}$ centred on Northern Territory, as well as a number of widely distributed taxa that extend westwards from Cape York and north-eastern Queensland. The northern and southern floristic regions do not contain distinct floristic elements, but rather contain taxa that extend from other areas; the northern region contains taxa mostly from floristic element $\mathrm{Al}$, and the southern region taxa entirely from element $\mathrm{B}$.

\section{Floristic regions from Cryptocarya}

The cluster analysis of the 10 geographic units (Fig. 10) shows that the primary division is between the northern area and all other areas, although the southern area is nearly as distinct. In general, however, these two areas have a relatively low number of taxa, and the major concentrations of taxa are in the north-eastern and south-eastern areas. The four-group level provides a convenient classification, and these four groupings are here recognized as: 


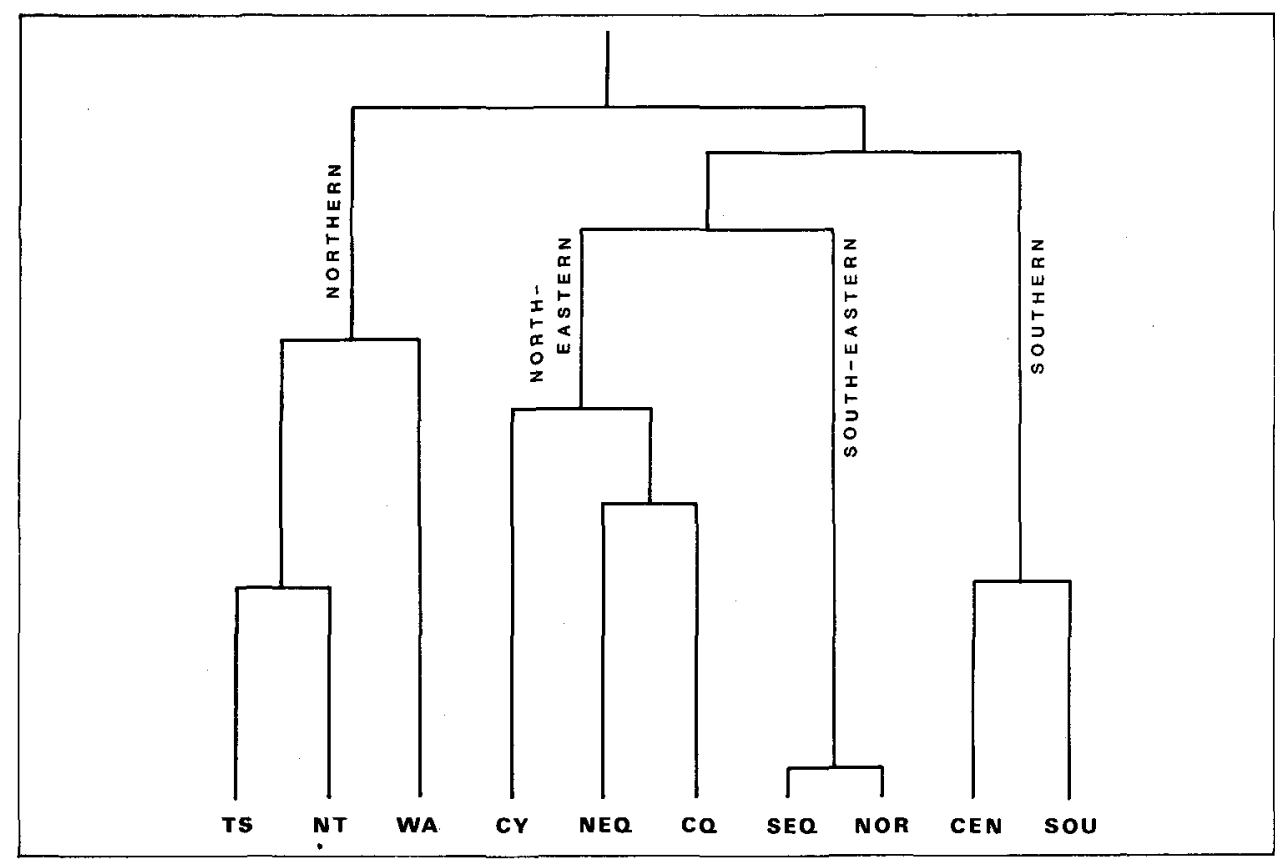

Figure 10. Cluster analysis of the 10 Australian geographic units in Cryptocarya showing the four floristic regions recognized.

(i) northern floristic region, comprising Torres Strait, Northern Territory and Western Australia

(ii) north-eastern floristic region, comprising Cape York, north-eastern Queensland and central Queensland

(iii) south-eastern floristic region, comprising south-eastern Queensland and northern New South Wales

(iv) southern floristic region, comprising central and southern New South Wales.

The analysis of these data by ordination shows a similar pattern of relationships (Fig. 11). The four floristic regions recognized in the cluster analysis are clearly seen in the ordination. The minimum spanning tree (Fig. 12) also supports the recognition of these regions.

\section{Floristic elements in Cryptocarya}

The cluster analysis of the 42 taxa (18 distribution patterns) on the basis of their distribution indicates that there are two major groupings, each of which may be further divided into two (Fig. 13, Table 3 ). These four groupings are here termed floristic elements.

Floristic element $\mathrm{A} 1$ is basically a northern element, and contains five taxa that are generally centred on Cape York. Three of these taxa are endemic to Cape York, while the other two extend to New Guinea and, in one case, beyond.

Floristic element A2 is basically a north-eastern element, with 23 taxa, all of which are to be found in north-eastern Queensland. Nine of these taxa are endemic to north-eastern Queensland, while the others are variously distributed southwards, northwards and westwards. Eleven taxa from this group reach central Queensland, but only three of these reach south-eastern Queensland and 


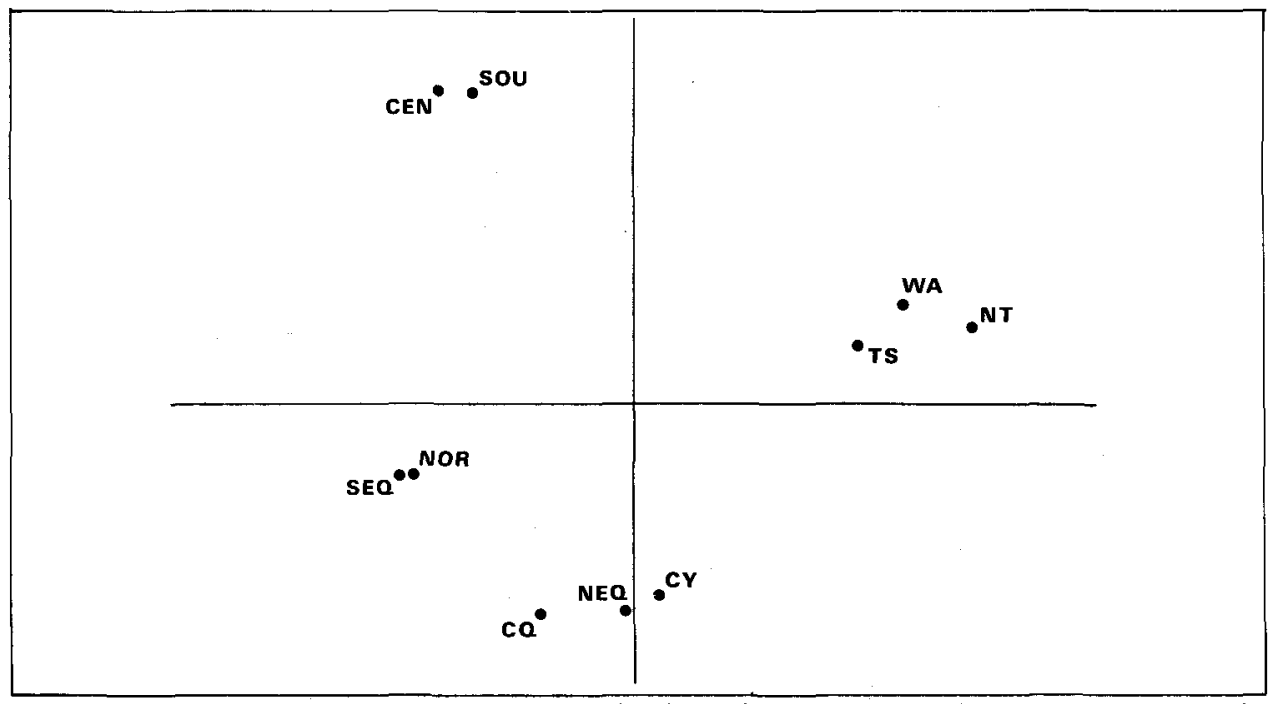

Figure 11. Principal co-ordinates analysis ordination of the 10 Australian geographic units in Cryptocarya (axis 1 accounts for $27 \%$ of the variation, and axis 2 for $23 \%$ ).

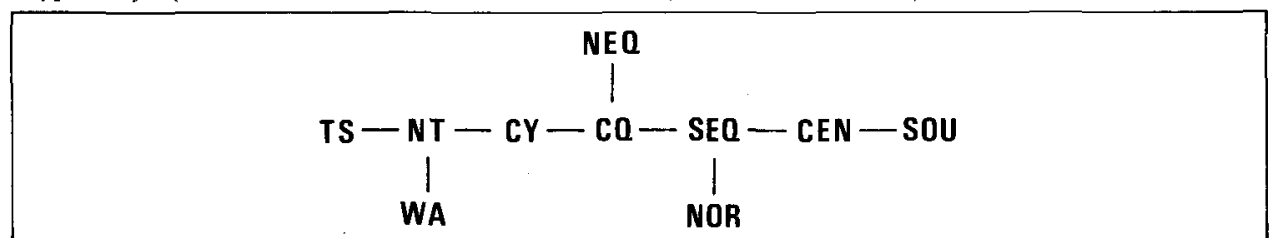

Figure 12. Minimum spanning tree of the 10 Australian geographic units in Cryptocarya.

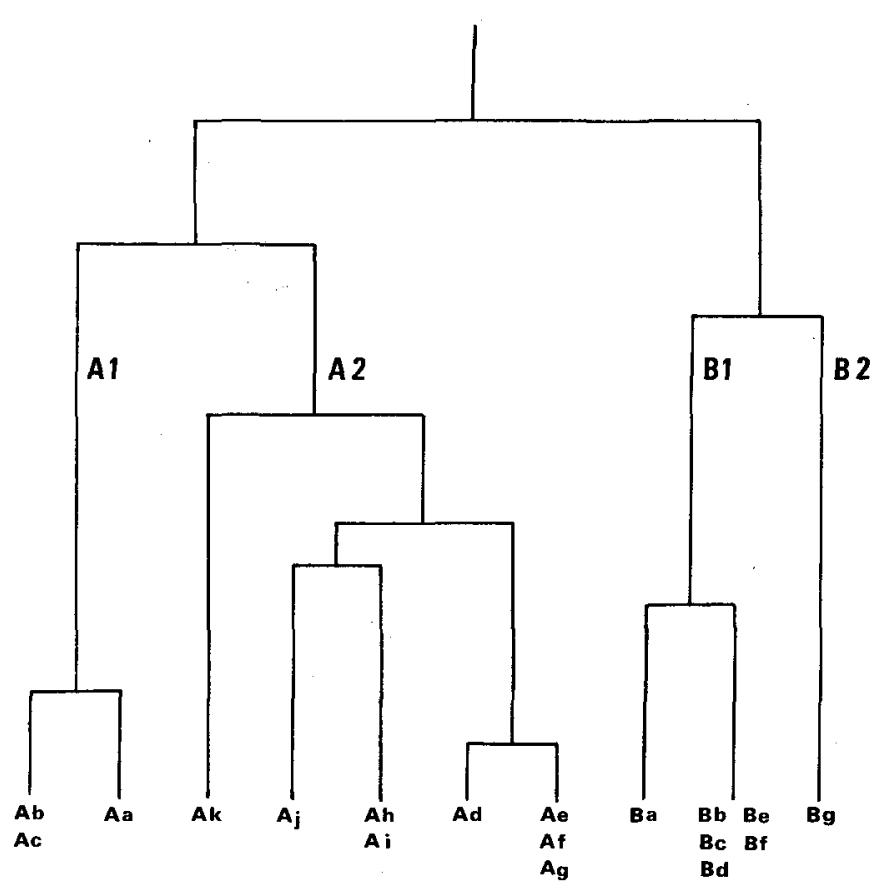

Figure 13. Cluster analysis of the 42 taxa (18 distribution patterns) of Cryptocarya showing the four floristic elements recognized. 
TABLE 3. DISTRIBUTION PATTERNS IN CRYPTOCAR YA, INDICATING THE FOUR FLORISTIC ELEMENTS RECOGNIZED

\begin{tabular}{|c|c|c|c|c|c|c|c|c|c|c|c|c|c|c|c|c|c|c|c|}
\hline Floristic element & \multicolumn{3}{|c|}{$\mathbf{A 1}$} & \multicolumn{8}{|c|}{$\mathbf{A 2}$} & \multicolumn{6}{|c|}{ B1 } & $\mathbf{B 2}$ & Total \\
\hline $\begin{array}{l}\text { Southern N.S.W. } \\
\text { Central N.S.W. } \\
\text { Northern N.S.W. } \\
\text { South-eastern Qid } \\
\text { Central Qld } \\
\text { North-eastern QId } \\
\text { Cape York } \\
\text { Northern Territory } \\
\text { Western Australia } \\
\text { Torres Strait } \\
\text { New Guinea } \\
\text { Malesia } \\
\text { 'Widespread' }\end{array}$ & $\mathrm{X}$ & $\mathrm{X}$ & $\begin{array}{l}X \\
X \\
X\end{array}$ & $\mathrm{X}$ & $\begin{array}{l}X \\
X\end{array}$ & $\begin{array}{l}\mathbf{X} \\
\mathbf{X} \\
\mathbf{X}\end{array}$ & $\underset{X}{X}$ & $\begin{array}{l}\text { X } \\
\text { X } \\
\text { X } \\
\text { X } \\
\text { X }\end{array}$ & $\begin{array}{l}\mathbf{X} \\
\mathbf{X} \\
\mathbf{X} \\
\mathbf{X} \\
\mathbf{X} \\
\mathbf{X} \\
\\
\mathbf{X}\end{array}$ & $\begin{array}{l}\mathbf{X} \\
\underset{X}{X} \\
\mathbf{X}\end{array}$ & $\begin{array}{l}\text { X } \\
\\
\text { X } \\
\text { X }\end{array}$ & $\mathrm{X}$ & $\stackrel{\mathrm{X}}{\mathrm{X}}$ & $\begin{array}{l}\mathrm{X} \\
\mathrm{X}\end{array}$ & $\begin{array}{l}\mathrm{X} \\
\mathrm{X}\end{array}$ & $\begin{array}{l}X \\
X \\
X\end{array}$ & $\begin{array}{l}\mathbf{X} \\
\mathbf{X} \\
\mathbf{X} \\
\mathbf{X} \\
\mathbf{X}\end{array}$ & $\mathrm{X}$ & $\begin{array}{r}1 \\
2 \\
15 \\
14 \\
14 \\
23 \\
14 \\
2 \\
1 \\
1 \\
2 \\
1 \\
2\end{array}$ \\
\hline $\begin{array}{l}\text { Distribution pattern } \\
\text { Number of taxa }\end{array}$ & $\underset{3}{\mathrm{Aa}}$ & $\underset{1}{\mathrm{Ab}}$ & $\underset{1}{\mathrm{Ac}}$ & $\underset{9}{\mathrm{Ad}}$ & $\underset{4}{\mathrm{Ae}}$ & $\underset{4}{\mathrm{Af}}$ & $\mathrm{Ag}$ & $\underset{2}{\mathrm{Ah}}$ & $\underset{1}{\mathrm{Ai}}$ & $\stackrel{\mathrm{Aj}}{1}$ & $\underset{1}{A k}$ & $\mathrm{Ba}$ & $\stackrel{\mathrm{Bb}}{6}$ & $\begin{array}{c}\mathrm{Bc} \\
1\end{array}$ & $\begin{array}{c}\mathrm{Bd} \\
1\end{array}$ & $\begin{array}{c}\mathrm{Be} \\
1\end{array}$ & $\begin{array}{c}\mathrm{Bf} \\
1\end{array}$ & $\frac{\mathrm{Bg}}{3}$ & \\
\hline
\end{tabular}


northern New South Wales. Nine taxa are found in Cape York, but only one of these reaches Torres Strait. Two taxa extend to Northern Territory, and one of these also reaches Western Australia.

Floristic element B1 is basically a south-eastern element, and contains 11 taxa, all of which are to be found in south-eastern Queensland, and all but two in northern New South Wales. Seven taxa are endemic to the south-eastern Queensland-northern New South Wales area, while the others are variously distributed to the north and south. Three taxa of this element extend to central Queensland, while two extend to central New South Wales, with one reaching southern New South Wales.

Floristic element B2 is a southern element, containing three taxa only, all of which are endemic to northern New South Wales. It is thus distinguished basically by its narrow endemic status. The three taxa in floristic element B2 are not presently known from south-eastern Queensland, whereas all members of element $\mathrm{B} 1$ are to be found there.

The analyses of these taxa by ordination (Fig. 14) and minimum spanning tree (Fig. 15) also indicate this primary division into a northern and western grouping on the one hand and a southern and south-eastern grouping on the other, and also give additional information on the interrelationships of the elements. Floristic element $\mathrm{A} 1$ is quite distinct from $\mathrm{A} 2$, as can also be seen in the cluster analysis (Fig. 13). Floristic element B2 is not really distinct from B1 on axes 1 and 2 (Fig. 14), but is distinct on later axes. There is a reasonably clear separation of $\mathrm{A} 2$ and $\mathrm{B} 1$, but the distribution patterns $\mathrm{Ah}$ and $\mathrm{Ai}$ can be seen to be somewhat intermediate between the two (Fig. 14). These are the only distribution patterns within A2 that extend into south-eastern Queensland and northern New South Wales, and so this intermediacy is not surprising.

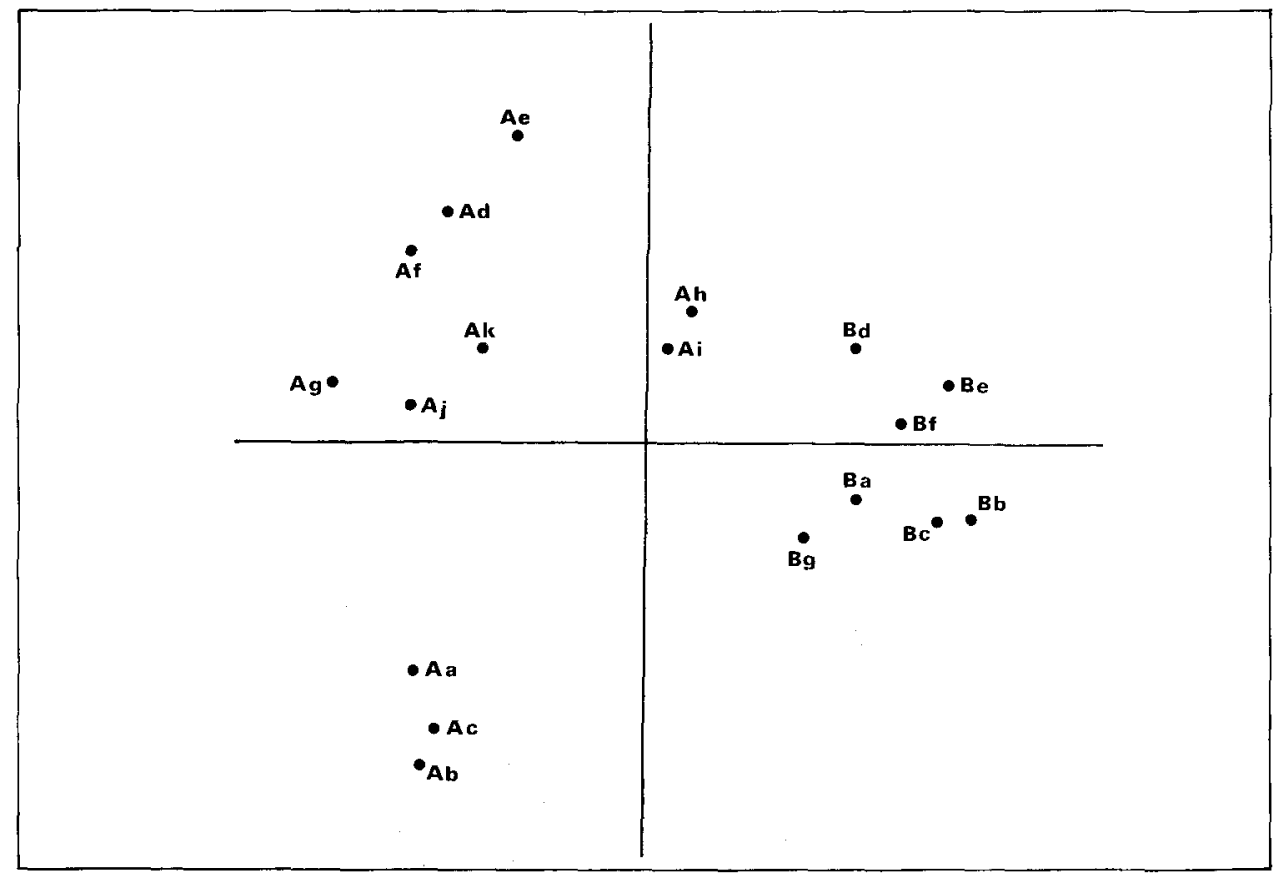

Figure 14. Principal co-ordinates analysis ordination of the 42 taxa (18 distribution patterns) of Cryptocarya (axis 1 accounts for $26 \%$ of the variation, and axis 2 for $16 \%$ ). 


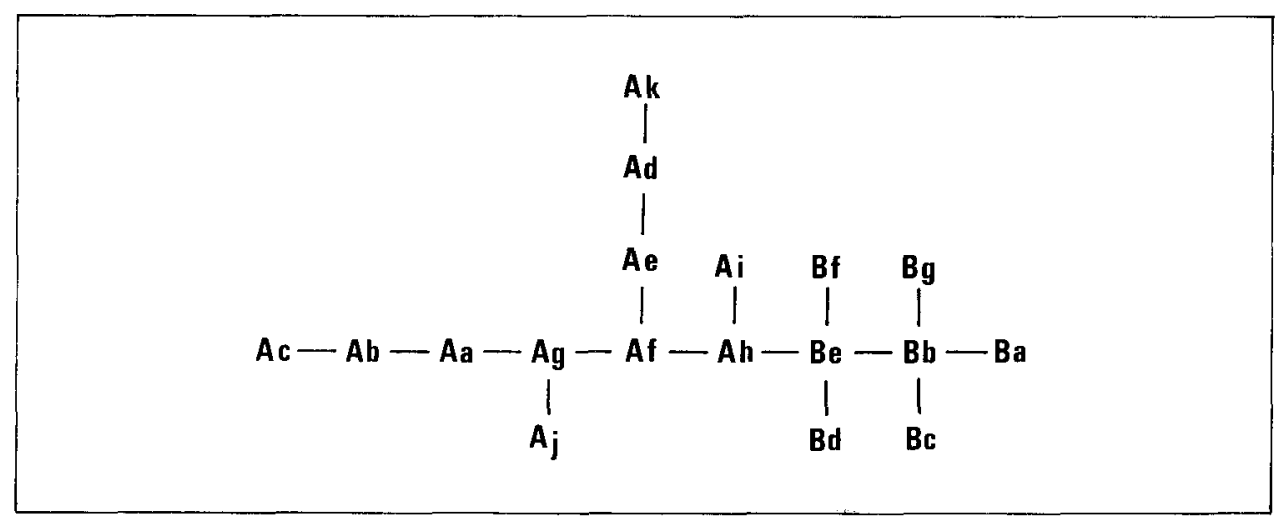

Figure 15. Minimum spanning tree of the 42 taxa (18 distribution patterns) of Cryptocarya.

\section{Comparison of floristic regions and floristic elements in Cryptocarya}

The relationships between the floristic regions and the floristic elements in Cryptocarya may be seen in Table 4 . When considered with the distribution data in Table 3 , this tends to indicate that two of the regions have a sound basis in floristic elements, whereas the other two do not. The north-eastern floristic region is based to a reasonable extent on floristic element $A 2$, and the south-eastern floristic region is based on floristic element B1. The northern floristic region contains taxa extending into it that are part of floristic element A2, while the southern floristic region contains taxa extending into it that are part of floristic element B1. The north-eastern and south-eastern floristic regions are largest, and most complex, each containing parts of three floristic elements, while the northern and southern floristic regions each contain only one element, and that not an endemic one.

TABLE 4. SPECIES IN COMMON BETWEEN FLORISTIC ELEMENTS AND FLORISTIC REGIONS IN CR YPTOCAR YA

\begin{tabular}{cccccc}
\hline \multirow{2}{*}{$\begin{array}{c}\text { Floristic } \\
\text { element }\end{array}$} & northern & north-eastern & south-eastern & southern & $\begin{array}{c}\text { Number } \\
\text { of taxa }\end{array}$ \\
\cline { 2 - 5 } & 0 & 5 & 0 & 0 & 5 \\
A1 & 2 & 23 & 3 & 0 & 23 \\
A2 & 0 & 3 & 11 & 2 & 3 \\
B1 & 0 & 0 & 3 & 0 & \\
B2 & 2 & 31 & 17 & 2 & \\
Total & & & & \\
\hline
\end{tabular}

\section{Comparison of Syzygium and allied genera and Cryptocarya}

As might be expected, the floristic regions recognized from the two data sets are reasonably similar, especially if due allowance is made for the uncertainty of the positions of central Queensland and Cape York in the analyses of the data set from Syzygium and allied genera. In each case there is a reasonably consistent recognition of a north-eastern, south-eastern and southern region. The major difference is that in Syzygium and allied genera there is a division of the northern floristic region into two, producing a smaller northern and a new north-western floristic region. This is reflected also in the floristic elements, and presumably relates to a slightly different evolutionary history in the two groups. 
There are many similarities also in the floristic elements recognized in the two groups. In each case there is the recognition of a distinct north-eastern floristic element, centred on north-eastern Queensland. This is the largest element in each group, and contains a significant number of endemic taxa. There is also, in each group, a distinct south-eastern element, also with a significant number of endemic taxa. Also within each group there is a distinct northern floristic element, centred on Cape York. This element contains some endemic taxa, and others that generally extend northwards but not southwards.

The main differences between the two groups lie in the recognition within Syzygium and allied genera of a north-western floristic element, centred on Northern Territory, with two endemic taxa, and two taxa that extend westwards or northwards, but not eastwards. Cryptocarya does not show a north-western element, but it does show a more distinctive northern New South Wales endemic element.

\section{Patterns of diversity, endemism and floristic element distribution}

It is now of interest to consider the flora of the various geographic units in more detail, taking account of the number of taxa, number of endemic taxa, and floristic element composition of each geographic unit in turn. This information is summarized in Table 5 for Syzygium and allied genera, and Table 6 for Cryptocarya. The geographic units are those used in the analyses for floristic regions and floristic elements, except that south-eastern Queensland and northern New South Wales are combined, as they proved to be very similar (Figs 4 and 10).

Within Syzygium and allied genera (Table 5), it is found that north-eastern Queensland has by far the largest number of taxa, and the largest number and highest percentage of endemic taxa. Cape York has a relatively large number of taxa but a relatively low percentage of endemics; Northern Territory has fewer taxa, but an equivalent number of them are endemic. South-eastern Queensland-northern New South Wales has a relatively small number of taxa, but a higher proportion of them are endemic. Central Queensland, however, has only a few less taxa, but none of them is endemic.

TABLE 5. DIVERSITY, ENDEMISM AND REPRESENTATION OF FLORISTIC ELEMENTS IN THE MAIN GEOGRAPHIC AREAS OF AUSTRALIA FOR SYZYGIUM AND ALLIED GENERA

\begin{tabular}{|c|c|c|c|c|c|c|c|c|c|}
\hline \multirow[b]{2}{*}{ Geographic area } & \multirow{2}{*}{ 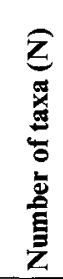 } & \multirow{2}{*}{ 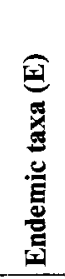 } & \multirow{2}{*}{ 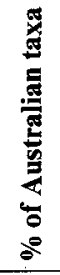 } & \multirow{2}{*}{$\frac{\widehat{o}}{\underline{z}}$} & \multirow{2}{*}{ 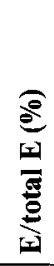 } & \multicolumn{4}{|c|}{ Floristic element } \\
\hline & & & & & & $\overline{A 1}$ & $\overline{\mathrm{A2}}$ & B & $\mathbf{C}$ \\
\hline Torres Strait & 7 & 0 & 10 & 0 & 0 & 5 & 2 & 0 & 0 \\
\hline Western Australia & 5 & 0 & 7 & 0 & 0 & 0 & 4 & 0 & 1 \\
\hline Northern Territory & 12 & 2 & 17 & 17 & 6 & 0 & 8 & 0 & 4 \\
\hline Cape York & 25 & 5 & 36 & 20 & 14 & 10 & 15 & 0 & 0 \\
\hline North-eastern Qld & 46 & 23 & 67 & 50 & 66 & 1 & 41 & 4 & 0 \\
\hline Central Qld & 10 & 0 & 14 & 0 & 0 & 0 & 7 & 3 & 0 \\
\hline SE. Qld-N. N.S.W. & 14 & 5 & 20 & 36 & 14 & 0 & 2 & 12 & 0 \\
\hline Central N.S.W. & 4 & 0 & 6 & 0 & 0 & 0 & 0 & 4 & 0 \\
\hline Southern N.S.W. & 3 & 0 & 4 & 0 & 0 & 0 & 0 & 3 & 0 \\
\hline Victoria & 1 & 0 & 1 & 0 & 0 & 0 & 0 & 1 & 0 \\
\hline
\end{tabular}


Central Queensland is of interest, lying as it does geographically between the two major centres of diversity and endemism. Central Queensland, with a local flora of 10 taxa, has no endemics. Seven of the 10 taxa come from floristic element A2, and three from element B. Although the number coming from north-eastern Queensland is higher than that coming from south-eastern Queensland, if the non-endemic flora of the two areas are considered (23 and nine respectively), the proportions coming from north and south appear more equal.

Many similarities, and a few differences, are seen in the patterns in Cryptocarya (Table 6). The main area of diversity is north-eastern Queensland; however, while south-eastern Queensland-northern New South Wales has a lower diversity, it has a larger number, and a notably higher proportion, of endemic taxa. Cape York has a similar number of taxa to south-eastern Queensland, but a much lower number of endemics, while central Queensland also has a similar number of taxa, but with no endemics.

TABLE 6. DIVERSITY, ENDEMISM AND REPRESENTATION OF FLORISTIC ELEMENTS IN THE MAIN GEOGRAPHIC AREAS OF AUSTRALIA FOR CR YPTOCAR YA

\begin{tabular}{|c|c|c|c|c|c|c|c|c|c|}
\hline \multirow[b]{2}{*}{ Geographic area } & \multirow{2}{*}{ 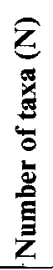 } & \multirow{2}{*}{ 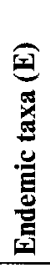 } & \multirow{2}{*}{ 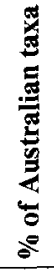 } & \multirow{2}{*}{$\underset{z}{E}$} & \multirow{2}{*}{ 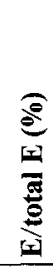 } & \multicolumn{4}{|c|}{ Floristic element } \\
\hline & & & & & & A1 & A2 & B1 & B2 \\
\hline Torres Strait & 1 & 0 & 2 & 0 & 0 & 0 & 1 & 0 & 0 \\
\hline Western Australia & 1 & 0 & $\overline{2}$ & 0 & 0 & 0 & 1 & 0 & 0 \\
\hline Northern Territory & 2 & 0 & 5 & 0 & 0 & 0 & 2 & 0 & 0 \\
\hline Cape York & 14 & 3 & 33 & 21 & 14 & 5 & 9 & 0 & 0 \\
\hline North-eastern Qld & 23 & 9 & 55 & 39 & 41 & 0 & 23 & 0 & 0 \\
\hline Central Q1d & 14 & 0 & 33 & 0 & 0 & 0 & 11 & 3 & 0 \\
\hline SE. QId-N. N.S.W. & 17 & 10 & 40 & 59 & 45 & 0 & 3 & 11 & 3 \\
\hline Central N.S.W. & 2 & 0 & 5 & 0 & 0 & 0 & 0 & 2 & 0 \\
\hline Southern N.S.W. & 1 & 0 & 2 & 0 & 0 & 0 & 0 & 1 & 0 \\
\hline
\end{tabular}

Central Queensland is again of interest, and the situation is similar to that found in Syzygium and allied genera. Central Queensland has no endemic taxa of Cryptocarya and, of its 14 taxa, 11 come from the north-eastern element A2 and three from the south-eastern element B1. There is thus a much greater input from the north than from the south; unlike the situation in Syzygium and allied genera, however, this conclusion is only modified slightly when consideration is taken of the larger number of taxa in north-eastern Queensland (23) than in south-eastern Queensland-northern New South Wales (17).

\section{Possible relationships with past migration and evolution}

The pattern of distribution of the floristic elements provides some interesting insights into past evolution and migration. Jardine (1972) points out that the tendency for species distributions to fall into clusters may provide clues to past areas of isolation and subsequent dispersal. Centres of species concentration of particular elements may be related to past areas of isolation in which differentiation may have occurred and that may have acted as centres for refuge and subsequent dispersal. 
In both Syzygium and allied genera and Cryptocarya there are two major centres of species concentration and endemism, being north-eastern Queensland and south-eastern Queensland-northern New South Wales. Each has a major floristic element centred there, which provides most of the local species, with a much smaller number of species coming from other floristic elements. These two areas are marked centres of concentration in both taxonomic groups; only difference is that in Cryptocarya the south-eastern Queensland-northern New South Wales area is more important both for diversity and for endemism than it is in Syzygium and allied genera.

There are two minor centres of species concentration in Cape York and Northern Territory. These show a small endemic component and a number of species centred there, but with a larger number of species coming from floristic elements centred elsewhere. Cape York is seen as a minor centre in both taxonomic groups, whereas Northern Territory is only a centre in Syzygium and allied genera.

These four areas presumably represent long-term refuges and centres of isolation, in which species have originated and from which they have dispersed under favourable conditions. These areas are known as refuge areas from a number of other studies that have been summarized recently in Keast (1981); they represent significant areas of rainforest vegetation today. Northern Territory is less often seen as a refuge, and in Syzygium and allied genera it presumably relates to species with an adaptation to drier or monsoonal rainforest conditions.

All other areas are seen, in more recent times at least, as immigrant areas, receiving their flora from one or more of the centres of isolation. These areas in each case have received their flora from the geographically closest refuge areas. Where there is only one close refuge area, as in the case of central and southern New South Wales, the flora contains only one floristic element. Where there are two or more close refuge areas the flora reflects this, as can be seen in central Queensland.

\section{CONCLUSIONS}

The study of the distribution patterns shown by these two groups has led to ideas on the evolution and migration of the various taxa within Australia that relates well with the known biogeographic history of these areas. This present study should be seen only as the first step, with further investigation required in two main areas. Firstly, a more detailed knowledge of the relationships of the individual species will allow much more definite statements about the lines of evolution within these taxonomic groups, and will enable quantification of some of the relationships discussed here. Secondly, studies on further genera are required, so that integration of the individual results will allow the major patterns of relationships of Australian rainforest plants to be determined.

\section{ACKNOWLEDGMENTS}

We wish to thank Rhonda Parish for technical assistance, and Jo Cook for preparing the figures. 


\section{REFERENCES}

Birks, H. J. B. (1976). The distribution of European pteridophytes: a numerical analysis. New Phytol. 77: 257-287.

Briggs, B. G. \& Johnson, L. A. S. (1979). Evolution in the Myrtaceae -evidence from inflorescence structure. Proc. Linn. Soc. New South Wales 102: 157-256.

Clifford, H. T. \& Williams, W. T. (1973). Classificatory dendrograms and their interpretation. Austral. J. Bot. 21: 151-162.

Hopper, S. D. \& Maslin, B. R. (1978). Phytogeography of Acacia in Western Australia. Austral. J. Bot. 26: 63-78.

Hutchinson, J. (1964). 'Genera of Flowering Plants' (Clarendon Press: Oxford) vol. 1.

Hyland, B. P. M. (1983). A revision of Syzygium and allied genera (Myrtaceae) in Australia. Austral. J. Bot. Suppl. Ser. 9: 1-164.

Jardine, N. (1972). Computational methods in the study of plant distributions. In Valentine, D. H. (Ed.), 'Taxonomy, Phytogeography and Evolution' (Academic Press: London) pp. 381-393.

Keast, A. (Ed.) (1981). 'Ecological Biogeography of Australia' (W. Junk: The Hague) 3 vols.

Schmid, R. (1972). A resolution of the Eugenia-Syzygium controversy (Myrtaceae). Amer. J. Bot. 59: 423-436.

Webb, L. J. \& Tracey, J. G. (1981a). Australian rainforests: patterns and change. In Keast, A. (Ed.), 'Ecological Biogeography of Australia' (W. Junk: The Hague) vol. 1, pp 605-694.

Webb, L. J. \& Tracey, J. G. (1981b). The rainforests of northern Australia. In Groves, R. H. (Ed.), 'Australian Vegetation' (Cambridge Univ. Press: Cambridge) pp. 67-101.

Whiffin, T. (1982). Variation and evolution in the genus Flindersia (Rutaceae). II. Review of methods for geographic variation analysis of volatile oil data. Austral. J. Bot. 30: 645-657.

\section{APPENDIX 1}

Composition of the distribution patterns and floristic elements in Syzygium and allied genera. ( $S=$ Syzygium, A=Acmena, Acm = Acmenosperma, $W=$ Waterhousea).

\section{Floristic element A1}

Aa - $A$. mackinnoniana, $S$. argyropedicum, $S$. bamagense, $S$. macilwraithianum, $S$. velae. Ab $-S$. bungadinnia. Ac $-S$. aqueum. Ad $-S$. branderhorstii. Ae $-S$. buettneranum, $S$. sayeri. Af $-S$. amplum. $\mathrm{Ag}-S$. puberulum.

\section{Floristic element A2}

Ah - A. divaricata, A. graveolens, A. hemilampra subsp. orophila, $S$. alatoramulum, $S$. alliiligneum, $S$. boonjee, $S$. canicortex, $S$. dansiei, $S$. erythrocalyx, S. erythrodoxum, $S$. gustavioides, $S$. kuranda, $S$. papyraceum, $S$. pseudofastigiatum, S. rubrimolle, S. sharonae, S. trachyphloium, S. wilsonii subsp. wilsonii, S. xerampelinum, $W$. hedraiophylla, $W$. mulgraveana, $W$. unipunctata, Acm. pringlei. Ai - S. apodophyllum, S. banksii, S. cormiflorum. $\mathrm{Aj}-A$. resa, $S$. endophloium, $S$. wesa. Ak $-S$. johnsonii. Al $-S$. wilsonii 
subsp. cryptophlebium. Am $-A$. hemilampra subsp. hemilampra. An $-S$. angophoroides, S. eucalyptoides subsp. eucalyptoides, $S$. forte subsp. potamophilum. Ao $-S$. suborbiculare. Ap $-S$. fibrosum, S. forte subsp. forte. $\mathrm{Aq}-S$. malaccense. Ar $-S$. tierneyanum. As - Acm. claviflorum.

\section{Floristic element B}

$\mathrm{Ba}-A$. brachyandra, $S$. crebrinerve, $S$. francisii, $S$. hodgkinsoniae, $S$. moorei. $\mathrm{Bb}-S$. corynanthum, $S$. luehmannii. $\mathrm{Bc}-W$. floribunda. $\mathrm{Bd}-S$. oleosum. $\mathrm{Be}-S$. australe. $\mathrm{Bf}-A$. smithii. $\mathrm{Bg}-S$. paniculatum.

Floristic element $\mathbf{C}$

$\mathrm{Ca}-S$. armstrongii, S. minutuliflorum. $\mathrm{Cb}-S$. eucalyptoides subsp. bleeseri. $\mathrm{Cc}-S$. operculatum.

\section{APPENDIX 2}

Composition of the distribution patterns and floristic elements in Cryptocarya (as the taxonomic study of this genus is still progressing, informal names are used for the undescribed species).

\section{Floristic element A1}

$\mathrm{Aa}-C$. sp. aff. microneura, $C$. sp. aff. rigida Claudie River, $C$. sp. Bamaga. $\mathrm{Ab}-C$. sp. aff. mackinnoniana. Ac - C. ilocana.

\section{Floristic element A2}

Ad $-C$. sp. aff. corrugata, $C$. glabella, $C$. hypoglauca, $C$. oblata, $C$. sp. aff. rigida, $C$. sp. Bellenden Ker, C. sp. Blue Laurel, $C$. sp. Coconut Laurel, $C$. sp. Emerald L.A. Ae $-C$. angulata, C. corrugata, C. murrayi, $C$. sp. aff. murrayi. Af $-C$. cinnamomifolia, $C$. sp. aff. cinnamomifolia, $C$. hypospodia, $C$. sp. aff. hypospodia. $\mathrm{Ag}-C$. mackinnoniana. $\mathrm{Ah}-C$. rigida, C. triplinervis. $\mathrm{Ai}-C$. bidwillii. $\mathrm{Aj}-C$. cunninghamii. $\mathrm{Ak}-C$. laevigata var. laevigata.

\section{Floristic element B1}

$\mathrm{Ba}-C$. sp. aff. bidwillii. $\mathrm{Bb}-$ C. erythroxylon, C. floydii, C. foveolata, $C$. laevigata var. bowiei, $C$. meisnerana, $C$. obovata. $\mathrm{Bc}-C$. microneura. $\mathrm{Bd}-C$. sp. aff. cunninghamii. $\mathrm{Be}-C$. foetida. $\mathrm{Bf}-C$. glaucescens.

\section{Floristic element B2}

$\mathrm{Bg}-C$. sp. Dome Mountain, $C$. sp. New England, $C$. sp. Willi Willi. 